\title{
INFRASTRUCTURE, INTERNET INCLUSIVENESS AND E-COMMERCE: AN EXPLORATORY STUDY
}

\author{
Frederick K. Augustine, Jr, Stetson University, faugusti@stetson.edu \\ John Rasp, Stetson University, jrasp@stetson.edu \\ Giao P. Nguyen, Stetson University, gnguyen@stetson.edu
}

\begin{abstract}
Almost any discussion of E-Business and E-Commerce includes references to the global nature of the World Wide Web, the rapidly increasing number of people around the world who have Internet access and to how the Web's global reach is affecting the growth and development of the world economy. At the macro or national level, research has been done to examine the growth of E-Business in Developing nations and cultural determinants of E-Commerce adoption at a national level and in relationship to the digital divide. Our research extends this line of inquiry by examining the basic relationship between E-Commerce and infrastructure at the national level.
\end{abstract}

Keywords: E-Commerce, Internet Infrastructure, Internet Inclusiveness, Information and Communications Technologies

\section{INTRODUCTION}

Over the past few decades, the Internet and networking technologies have been one of the main arenas for growth in the global business community. The establishment of the digital infrastructure has allowed for the development of an innovative way of conducting business that transcends borders: electronic commerce. The capacity of the Internet to transform economies is unrivaled by more traditional business methods.

The impressive growth of E-Commerce has been facilitated by the increasing accessibility and reliability of the Internet. We focus on four particular drivers of this expansion: (1) the rapid expansion of availability of the Internet to an ever-growing number of persons, (2) the increased affordability of Internet access, as technology and connection costs have plummeted, (3) the ever-widening relevance of Internet resources (function, local language access, etc.) to broad swaths of the world's population, and (4) the readiness of a nation (infrastructure, cultural acceptance) to adopt E-Commerce.

In this paper we examine the relative importance of these four factors in driving the expansion of Electronic Commerce. Our approach is exploratory. That is, the analyses we present are more data-driven than dependent upon any particular prior theoretical framework. We view this as a strength, not a limitation. In any field of inquiry, determination of "what's happening" necessarily precedes theorizing regarding "why is it happening."

\section{E-Business and E-Commerce}

The terms E-Business and E-Commerce are often used synonymously but represent different concepts. E-Commerce has been defined as "use of the Internet, the World Wide Web (Web), and mobile apps and browsers running on mobile devices to transact business." E-Business, on the other hand "refer(s) primarily to the digital enabling of transactions and processes within a firm, involving information systems under the control of the firm ... (and) for the most part, in our view, e-business does not include commercial transactions involving an exchange of value across organizational boundaries. For example, a company's online inventory control mechanisms are a component of ebusiness, but such internal processes do not directly generate revenue for the firm from outside businesses or consumers, as e-commerce, by definition, does” (Laudon and Traver, 2020, pg. 9). Most sources categorize ECommerce defining four basic models. These are Business to Consumer (B2C), Business to Business B2B), Consumer to Consumer (C2C) and Consumer to Business (C2B). B2C E-Commerce "is the type of commerce transaction in which businesses sell products or services directly to consumers". The term has also been used to refer to the online 


\section{Issues in Information Systems}

Volume 21, Issue 3, pp.117-125, 2020

selling of products, or e-tailing, in which manufacturers or retailers sell their products to consumers over the Internet (What is B2C?, 2020). For the purposes of this paper, we will be addressing only B2C E-Commerce. Subsequent references to B2C E-Commerce will be stated simply as E-Commerce.

Almost any discussion of E-Business and E-Commerce includes references to the global nature of the World Wide Web, the rapidly increasing number of people around the world who have Internet access and to how the Web's global reach is affecting the growth and development of the world economy. According to Internet World Stats, the Internet Penetration Rate has increased by 1,167 \% over the period 2000 to 2020 (Internet World Stats, 2020). Along with the dynamic increase of worldwide Internet access, the extent of the expansion of E-Business has been well documented over the past two decades. This expansion has been so impressive that the annual revenue figures for global ECommerce has increased from \$1.336 Trillion in 2014 to \$3.535 Trillion in 2019 (Gagliardi, 2019 and Clement, 2020). It is also true than an increasingly large share of E-Commerce revenues (approximately 83\%) now originates outside of the United States (Young, 2020). This is a natural consequence of the truly global nature of the World Wide Web and increasing percentage of people who are connected to the Internet.

\section{Literature Review}

Our research centered upon the following question: What is the relationship, at a national level, between the functionality of Internet infrastructure and the growth of E-Commerce. The idea that this relationship does exist is not a matter of conjecture in this study. We assume that there is a relationship between these variables such that better Internet infrastructure should facilitate E-Commerce revenue growth (Dumičić, et al., 2018; Waseem, et al., 2019). One of the bases of this assumption is shown in Figure 1 which depicts the results of the 2019 Network Readiness Index analysis. This part of the analysis shows a clear relationship between the Network Readiness Index (NRI) and GDP Per Capita. This index, developed by the World Information Technology and Services Alliance was created to "provide, for the first time, a holistic framework for assessing the multi-faceted impact of ICT on society and the development of nations.” Here the NRI is compared with the Per Capita GDP of 120 nations..

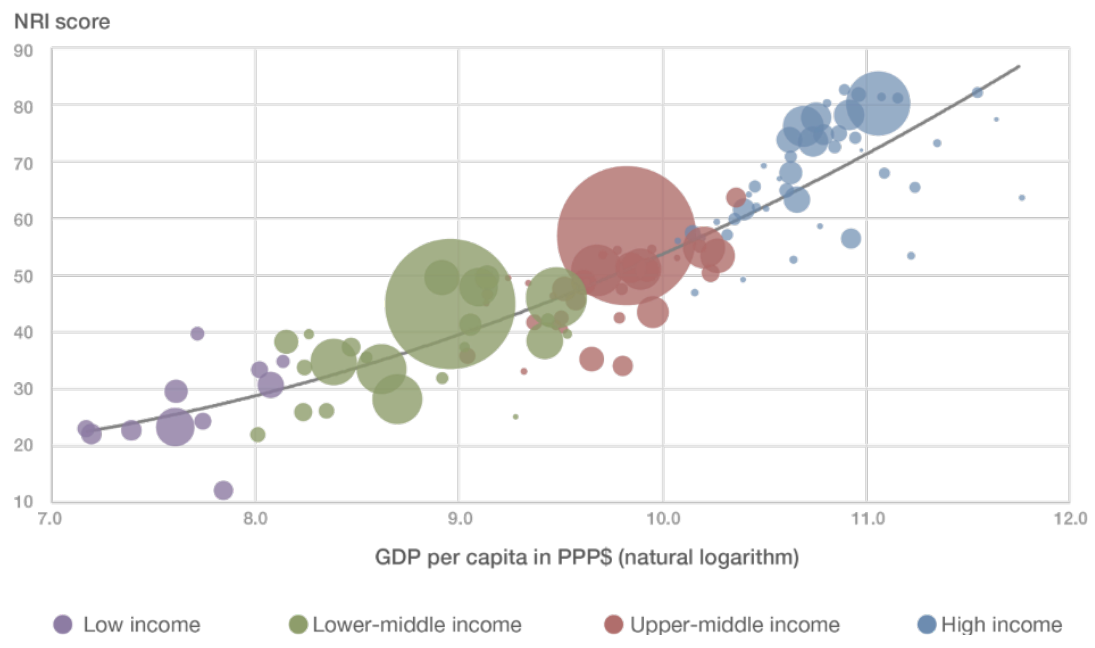

Figure 1. Network Readiness Index and Per Capita GDP

Another index that attempts to measure the use of technology is the Technology Readiness Index (TRI 2.0), a 16-item scale designed to measure people's propensity to embrace and use cutting-edge technologies (Parasuraman and Colby, 2014). This tool is designed to be used at the micro level for the purposes of customer segmentation with respect to technology readiness.

A variety of research studies have approached the global aspects of E-Commerce at the micro level, dealing with firms and industries in terms of issues such as consumer behavior (Shiu-Li, et al., 2019), socialization (Xintian \& Xiangdong, 2019), technology use, business factors (Gorla, et al., 2015), E-Commerce intensity (Kuresova \& Eger, 2017) and web site globalization (Augustine, et al., 2008). At the macro or national level, research has been done to 


\section{Issues in Information Systems}

Volume 21, Issue 3, pp.117-125, 2020

examine E-Commerce and economic growth (Hibner, 2012), the growth of E-Commerce in Developing nations (Dumičić, et al., 2018), and cultural determinants of E-Commerce adoption at a national level and in relationship to the digital divide (Makame, et al., 2014).

Our research extends this line of inquiry. Specifically, we examine the relationship between E-Commerce revenue at the national level and infrastructure at the national level. We do so using a multifaceted assessment of Internet participation, the Inclusive Internet Index (3i Index).

\section{The Inclusive Internet Index}

According to Business Standard (2020), the Inclusive Internet Index "benchmarks countries on the internet's availability, affordability, relevance and the readiness of people to use it. The annual report is commissioned by Facebook. In its fourth year, the index covered 100 countries, representing $91 \%$ of the world's population and $96 \%$ of global GDP.” This index represents a multi-dimensional measure of the electronic infrastructure of various nations. The $3 i$ Index, which polled more than 5,000 respondents from 100 countries, was developed as an approach to measure the effectiveness of existing Internet Infrastructures.

The overall index score is produced based on scores assigned for the Availability, Affordability, Relevance and Readiness categories. The Availability category "examines the quality and breadth of available infrastructure required for access and levels of Internet usage". Affordability "examines the cost of access relative to income and the level of competition in the Internet marketplace." Relevance "examines the existence and extent of local language content and relevant content" and Readiness "examines the capacity to access the Internet, including skills, cultural acceptance, and supporting policy.” (Inclusive Internet Index, 2020)

These four indexes are based upon both measurable values (such as the number of Internet users or Smartphone cost) and assessed perceptions on how the Internet use impacts individuals (such as the availability of basic information in the local language or social level of trust in online privacy). Each of the four main categories is further broken down into sub-categories. For example, Availability is expressed as a combination of Usage, Quality, Infrastructure and Access to Electricity. Each sub-category, in turn, is composed of various baseline statistics. As an example, the Readiness sub-category of Literacy consists of the following measures: Level of Literacy, Educational Attainment, Support for digital literacy and Level of web accessibility.

\section{METHODOLOGY}

This paper examines the effect of Internet Infrastructure as measured by the 3i Index on National Per Capita ECommerce revenue. The $3 \mathrm{i}$ Index was chosen over the NRI due to the fact that the NRI had undergone major revisions on more than one occasion. The $3 i$ Index has been computed in essentially consistent fashion throughout its four years of existence. Moreover, the $3 \mathrm{i}$ Index not only allows us to study the overall relationship between Internet use and Ecommerce economic growth, but also enables us to examine specific factors associated with that growth. This is due to the structure of the $3 \mathrm{i}$ Index, as a combination of relevant component and sub-component measures.

The research consists of two levels of analysis. The first level examined the relationship between each of the four major 3i Index categories (availability, affordability, relevance, readiness) and the economic impact of E-Commerce, as measured by National Per Capita E-Commerce revenue. Correlation and multiple regression analysis are used to model this relationship.

The second-level analysis delves further, by investigating how economic impact of E-commerce (again, as measured by National Per capita E-Commerce revenue) is related not to the four overall broad categories of the 3i Index, but by the various sub-category component measures. This allows us to see which particular aspects of the broad categories might have more material influence. Per Capita E-Commerce revenue data and Internet Inclusiveness data were available for a total of 77 nations. We focus the analysis upon data from the year 2019, the most recent available. 


\section{RESULTS}

\section{First Level Analysis}

This analysis consists of $3 \mathrm{i}$ Index data for the Overall $3 \mathrm{i}$ Index measure of effectiveness (obtained from the Inclusive Internet Index dataset), the four sub-categories measures described above, and E-Commerce Revenue Per Capita. Table 1 shows basic descriptive statistics calculated for each variable.

Table 1. Descriptive Statistics

\begin{tabular}{|l|c|c|}
\hline & Mean & $\begin{array}{c}\text { Standard } \\
\text { Deviation }\end{array}$ \\
\hline Overall Measure & 67.74 & 14.38 \\
\hline Availability & 63.88 & 16.87 \\
\hline Affordability & 68.55 & 15.49 \\
\hline Relevance & 74.23 & 15.94 \\
\hline Readiness & 67.73 & 11.31 \\
\hline E-C Revenue per Capita & 233.98 & 323.26 \\
\hline
\end{tabular}

The data displays moderate variation from country-to-country for each of the four major categories of the $3 \mathrm{i}$ Index as well as the overall measure. The smallest amount of variation occurs in the Readiness measure. It is also notable that the amount of variation in E-Commerce Revenue per Capita is quite high.

Figure 2 shows (graphically) the relationship between National E-Commerce Per Capita Revenue and the 3i Index overall measure of Internet Inclusiveness.

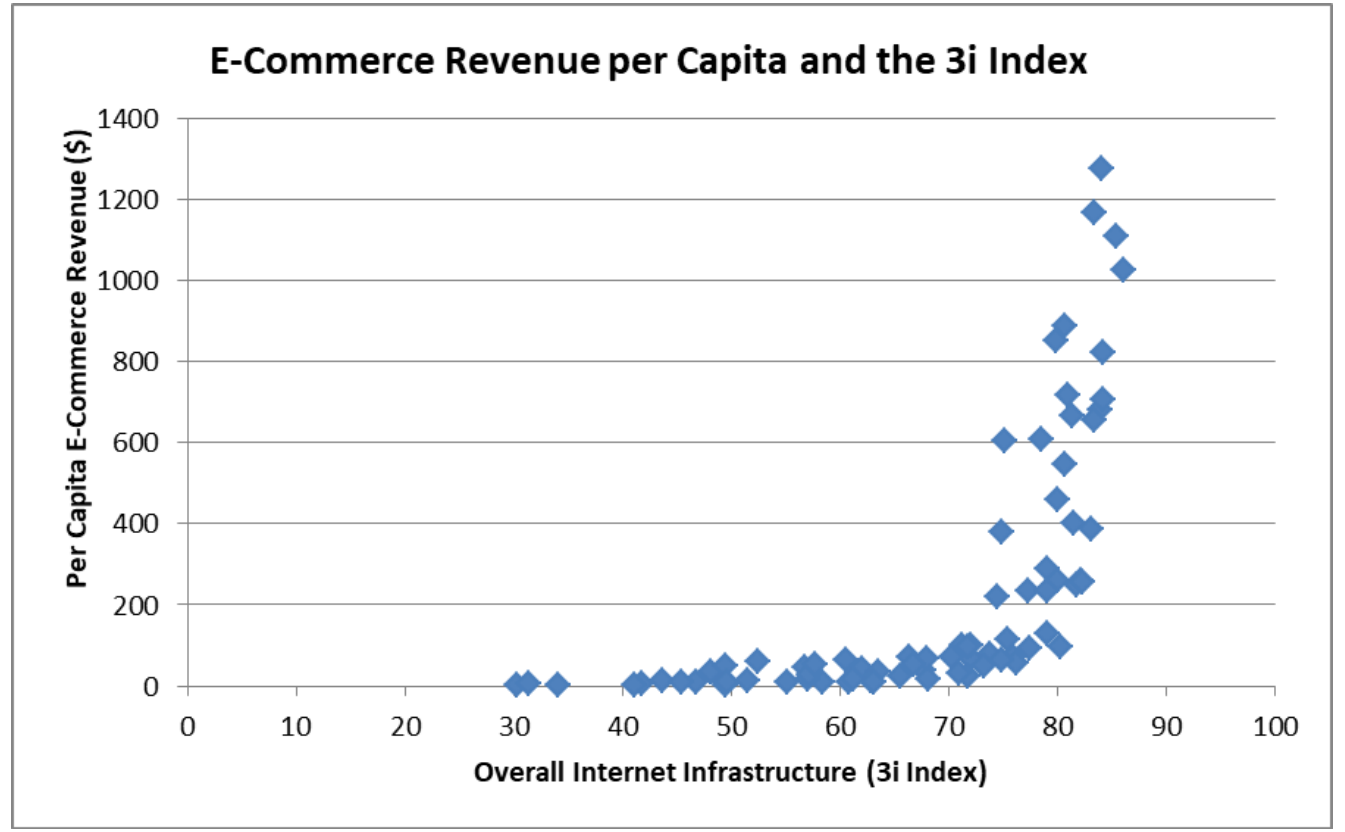

Figure 2. National E-Commerce Revenue Per Capita as a function of a country’s Overall 3i Index Measure

Note the relationship between Revenue Per Capita and the Overall measure. There is little or no payoff in terms of Per Capita Revenue until a basic threshold value of around 70 for the Overall measure is reached. We found that same phenomenon obtains in each of the four constituent measures; those graphs are not reproduced here. The exact point 


\section{Issues in Information Systems}

Volume 21, Issue 3, pp.117-125, 2020

at which the 'growth phase' kicks in differs slightly among the four major index categories, perhaps as low as 60 for Affordability and Readiness, and as high as 75 for Relevance. However, overall this indicates that there appears to be a minimum level of Internet Inclusiveness necessary to foster substantial E-Commerce revenue growth at a national level.

We used the logarithm (base 10) of Revenue Per Capita as the dependent variable in our Correlation and Multiple Regression Analysis against the four major 3i Index categories. Examination of the plots of each dependent variable with Revenue Per Capita reveals a non-linear, exponential growth pattern. This is not unusual in economic models; often the inputs have a multiplicative rather than additive effect upon financial outcomes. Plots of each dependent variable by Log Revenue Per Capita (not shown) reveal a general linear pattern, indicating that the log transformation is appropriate. Table 2 shows the results of the correlation analysis.

Table 2. Correlation Analysis

\begin{tabular}{|l|c|c|c|c|c|}
\hline & Availability & Affordability & Relevance & Readiness & $\begin{array}{c}\text { Log Rev } \\
\text { Per Capita }\end{array}$ \\
\hline Availability & 1 & & & & \\
\hline Affordability & 0.767 & 1 & & & \\
\hline Relevance & 0.859 & 0.740 & 1 & & \\
\hline Readiness & 0.679 & 0.559 & 0.712 & 1 & \\
\hline $\begin{array}{l}\text { Log Rev } \\
\text { Per Capita }\end{array}$ & 0.883 & 0.780 & 0.769 & 0.667 & 1 \\
\hline
\end{tabular}

The analysis shows that all four components are highly correlated with the Log Revenue per Capita variable. Availability displays the highest level of correlation. The t-scores and p-values associated with this analysis indicate that all four of the major category components are highly significant as predictors of Log E-Commerce Revenue Per Capita (p-values ranging from 1.29e-26 to 1.75e-11). It seems reasonable to suppose that Infrastructure Availability should be the first and possibly the most important step toward facilitating E-Commerce at the national level.

Multiple regression analysis of (log) per capita E-commerce revenue, using the four top-level components of the overall 3i Index measure as predictors, yielded an Adjusted r-square of .804, indicating that the four predictors jointly explain $80.4 \%$ of the variation in national-level $(\log )$ E-commerce revenue per capita. The F-test had a p-value of $1.57 \mathrm{e}-25$, indicating that the overall model is very significant. Table 3, below, gives the estimated intercept and slope coefficients from the multiple regression model, with associated test statistics. P-values are one-tailed, since we have a priori reason to believe a positive relationship between each predictor and E-commerce revenue, and are rounded to three decimals.

Table 3. Multiple Regression Analysis Results

\begin{tabular}{|l|c|c|c|c|}
\hline & Coefficient & $\begin{array}{c}\text { Standard } \\
\text { Error }\end{array}$ & t Stat & P-value \\
\hline Intercept & -1.2147 & 0.2492 & & \\
\hline Availability & 0.0307 & 0.0049 & 6.2583 & 0.000 \\
\hline Affordability & 0.0127 & 0.0040 & 3.1711 & 0.001 \\
\hline Relevance & -0.0049 & 0.0052 & -0.9395 & 0.351 \\
\hline Readiness & 0.0089 & 0.0050 & 1.7898 & 0.039 \\
\hline
\end{tabular}

The p-values for the Availability, Affordability and Readiness variables (highlighted) are significant at the .05 level. Thus we have reason to believe that these components contribute positively to economic value. Note that while each variable individually was significant (see Table 2), once they are combined the Relevance variable loses significance. 
Relevance does not have significant explanatory power, above and beyond that contributed by the other three toplevel measures.

\section{Second Level Analysis}

Data for a second-level analysis were obtained from the Inclusive Internet Index dataset. This analysis examines the relationship of the nine sub-component variables in the Index, with (log) E-Commerce Revenue per Capita. Correlations between each subcomponent, and Log Revenue per Capita generally show moderate to strong correlations (ranging from .897 for Usage to .497 for Policy. The exception is the Trust \& Safety variable, which is essentially uncorrelated with Log Revenue per Capita. The t-scores and p-values for all of the subcomponents are highly significant except for the "Trust and Safety" variable.

The results of the regression of the nine sub-component (dependent) variables to (log) Revenue per Capita shows that four of the variables (Usage, Price, Competitive Environment and Literacy) are significant based on their (one-tailed) p-values. Table 4, below, shows these results.

Table 4. Multiple Regression Analysis Results, from Subcomponent-Level Variables

\begin{tabular}{|l|c|c|c|c|}
\hline & Coefficient & $\begin{array}{c}\text { Standard } \\
\text { Error }\end{array}$ & t Stat & P-value \\
\hline Intercept & -1.1594 & 0.33494 & & \\
\hline Usage & 0.0177 & 0.00385 & 4.6034 & 0.000 \\
\hline Quality & 0.0070 & 0.00476 & 1.4796 & 0.072 \\
\hline Infrastructure & -0.0013 & 0.00375 & -0.3388 & 0.368 \\
\hline Electricity & 0.0019 & 0.00382 & 0.4994 & 0.310 \\
\hline Price & 0.0101 & 0.00566 & 1.7869 & 0.039 \\
\hline Competitive Environment & 0.0030 & 0.00162 & 1.8680 & 0.033 \\
\hline Local Content & -0.0014 & 0.00280 & -0.4839 & 0.315 \\
\hline Relevant Content & 0.0013 & 0.00532 & 0.2488 & 0.402 \\
\hline Literacy & 0.0067 & 0.00340 & 1.9705 & 0.027 \\
\hline Trust and Safety & 0.0026 & 0.00323 & 0.8113 & 0.210 \\
\hline Policy & -0.0003 & 0.00301 & -0.0871 & 0.465 \\
\hline
\end{tabular}

The number of dependent variables and the multicollinearity between the variables, combined with the preliminary and exploratory nature of the research, means that it is premature to posit definitive interpretation of these results. Nevertheless, the findings do offer several insights, and suggest various lines of further inquiry.

That the "Usage" variable is the sub-component most highly correlated with E-commerce revenue, and with most significant contribution in the multiple regression analysis, suggests that it is the prime driver of the E-commerce economic boom. This makes good sense - in order for E-commerce even to exist, individuals must of necessity be actually using the Internet. It also suggests a policy priority: that simply getting people connected is the first order of business, in terms of fostering E-commerce growth. We further note that, in the multiple regression, the "Infrastructure" and "Electricity" variables were not significant, once other factors were taken into account. This stands rather in contrast to the "if you build it, they will come" mantra of some development theorists. Here, it seems, simply having the structures in place for E-Commerce to exist is not enough to drive revenue; the populace must actually be moved to "Usage" of the Internet resource. The issues in developmental economics suggested here are well worth further study.

Relative importance of the "Price" and "Competitive Environment" sub-components suggest other policy priorities as well. The implication is that E-Commerce thrives best under a regime of inexpensive Internet connectivity available from a variety of competing suppliers. These issues appear to trump more nationalistic concerns, such as the 


\section{Issues in Information Systems}

Volume 21, Issue 3, pp.117-125, 2020

availability of locally-sourced or culturally-relevant content. Matters of localism versus globalism are becoming increasingly prominent in contemporary economic policy debate. Computer professionals likewise deal with the dynamics of local control versus world-wide scope of the Internet. The matters are worthy of much greater study, but this finding does lean toward the global-competitive rather than local-protectionist approach.

That the "Trust and Safety" variable is the one sub-component of the Index that is not at all correlated with ECommerce revenue is especially noteworthy. This variable aims to measure "Internet safety and cultural acceptance of the Internet," based upon a variety of factors, including level of privacy regulation, social trust in websites and social media, and a measure of E-commerce safety. Top score on this sub-component goes to Indonesia, with China a close second. Other nations in the top ten include Gabon, Rwanda, and Myanmar - none of which spring to mind as E-commerce hotspots. (South Korea, the United States, and Japan, by contrast, are $74^{\text {th }}, 75^{\text {th }}$, and $77^{\text {th }}$, respectively, among the 100 nations evaluated.) Any number of dynamics may be at work here. It may be, despite increased concerns in the Internet professional community regarding network security, that the populace as a whole does not perceive this to be a serious issue. It may be that E-Commerce has the ability to thrive in a wide variety of Internet safety environments. Or it may simply be that this particular component of the Internet Inclusivity Index is poorly constructed and lacking in face validity, and needs to be reworked. Again, further research is in order.

\section{SUMMARY}

It is clear that three of the four first-level variables (Availability, Affordability and Readiness) contribute to the economic value of E-Commerce at a national level when expressed per capita. It appears that there is a significant relationship between the Overall $3 \mathrm{i}$ Index measure and Per Capita E-Commerce revenue. It also appears that there is a basic threshold needed, in each of the four first-level component areas, before meaningful economic growth for ECommerce occurs. This phenomenon also occurs for each of the four constituent measures.

All four first-level components are highly significant predictors of economic activity. However, there is multicollinearity and Relevance does not add significant explanatory power, once the other three variables are in the model.

Our discussion of results, in the previous section, suggested some areas of potentially fruitful further investigation. We noted that Internet usage, more than simply its availability and infrastructure, appeared to be the essential issue. We found that Internet price and competitive environment appeared to be more important than local or cultural relevance. We found that Internet trust and safety concerns surprisingly did not appear to be at all relevant for Ecommerce revenue. Each of these findings must be viewed as very preliminary - this is, after all, only an exploratory study. However each is well worth investigating further, as they potentially have profound implications for the development of the Internet as an economic force.

An additional suggestion for further research would be to examine all 58 dependent variables which constitute the Inclusive Internet Index and determine which values are directly measurable and which have values which are determined via survey results and are thus subjective. The subjective variables could be eliminated from the model and then analyzed to determine if any of the non-significant second-level variables would become significant. We have also looked only at data from the most recent year available. Longitudinal analysis of several years of data would give additional insight into variables that drive growth in E-commerce revenue.

\section{REFERENCES}

Augustine, F., Surynt T., \& Jens, W. (2008). Global Readiness of E-Business Web Sites: An Industry Perspective, E-Business Review, Vol 8, No 1. (2008).

Clement, J., Global retail e-commerce sales 2014-2023, Statistica, Mar 19, 2020.

Dumičić, K., Bonić, I. S., \& Žmuk, B. (2018). Statistical analysis of the development indicators' impacts on Ecommerce of individuals in selected european countries. Nase Gospodarstvo : NG, 64(2), 15-24. 
Gagliardi, J. (2019). The Ever-Changing Face of E-Commerce: 1995-2020. E-Commerce Times, December 12, 2019.

Gorla, N. Chiravuri, A. and R. Chinta. (2015). Business to Business E-Commerce Adoption: An Empirical Investigation of Business Factors, Information Systems Frontiers, 19:645-667

Hassen, H., Rahim, N.H., \& Shah, A. (2019). Analysis of models for e-commerce adoption factors in developing countries.

Hibner, J. (2012). The development of an information society and electronic commerce in the European union in the context of selected documents of the EU and international organisations. Comparative Economic Research, 15(1).

Internet World Stats. (2020). Retrieved from https://www.internetworldstats.com/stats.htm, March, 2020.

Kunešová, H., \& Eger, L. (2017). Evaluation and Comparison of B2C E-Commerce Intensity in EU Member States. E+M Ekonomie a Management, 20(4), 151-167.

Lanvin, B and S. Dutta. (2019). WISTA Network Readiness Index 2019 Analysis. Retrieved from:

https://networkreadinessindex.org/nri-2019-analysis/\#analysis-and-results.

Laudon, K. and C. Traver. (2020). E-Commerce: Business, Technology, Society. Pearson Education, Inc., pg. 9.

Makame, W., Kang, J., \& Park, S. (2014). Factors influencing electronic commerce adoption in developing countries: The case of Tanzania. South African Journal of Business Management, 45(2), 83-96.

Mileros, M. D., Lakemond, N., \& Forchheimer, R. (2019). Towards a taxonomy of E-commerce: Characterizing content creator-based business models. Technology Innovation Management Review, 9(10), 62-77.

Oprescu, P. G. (2019). Influence of new technologies in E-commerce. Academy of Economic Studies. Economy Informatics, 19(1), 23-33.

Pakistan Ranked 76 ${ }^{\text {th }}$ out of 100 nations on Inclusive Internet Index. (2020, March 6). Business Standard. Retrieved from https://www.business-standard.com/article/international/pakistan-ranked-76th-out-of-100-nations-on-inclusiveinternet-index-2020-120030600014_1.html

Parasuraman, A. \& Colby, C. (2014). An Updated and Streamlined Technology Readiness Index: TRI 2.0. Journal of Service Research. 18(1), pp. 59-74.

Ramirez-Correa, P., Grandon, E \& Arenas-Gaitan, J. (2019). Assessing Differences in Customers’ Personal Disposition to E-Commerce. Industrial Management and Data Systems, 119(4), 792-820.

Shiu-Li, H., \& Ya-Chu, C. (2019). Cross-border e-commerce: Consumers' intention to shop on foreign websites. Internet Research, 29(6), 1256-1279.

Villa, E., Ruiz, L., Valencia, A., \& Picón, E. (2018). Electronic commerce: Factors involved in its adoption from a bibliometric analysis. Journal of Theoretical and Applied Electronic Commerce Research, 13(1), 39-70. 


\section{Issues in Information Systems}

Volume 21, Issue 3, pp.117-125, 2020

Waseem, A., Rashid, Y., Warraich, M., Sadiq, I., \& Shaukat, Z. (2019). Factors Affecting E-Commerce Potential of Any Country Using Multiple Regression Analysis. Journal of Internet Banking and Commerce; Ottawa, Vol. 14, Iss. 3, pp. 1-28.

What is B2C? (2020). Business News Daily, February 4, 2020. Retrieved from

https://www.businessnewsdaily.com/5085-what-is-b2c.html

Young, J. (2020). US ecommerce sales grow 14.9\% in 2019, Digital Commerce 360, Retrieved from https://www.digitalcommerce360.com/article/us-ecommerce-sales/, February 19, 2020.

Xintian, W., \& Xiangdong, W. (2019). Socialization, traffic distribution and E-commerce trends: An interpretation of the "pinduoduo" phenomenon. China Economist, 14(6), 56-72. 